\title{
THE EVOLUTION OF IDEAS CONCERNING RETINAL DETACHMENT WITHIN THE LAST FIVE YEARS*
}

\author{
BY \\ J. Gonin \\ PROFESSOR OF OPHTHALMOLOGY AT THE \\ UNIVERSITY OF LAUSANNE
}

\section{Mr. President, Ladies and Gentlemen,}

I deeply appreciate the honour of being awarded the William Mackenzie Memorial Medal, the more so that I understand it is only the second time that it has been bestowed on a non-British ophthalmologist ; the name of William Mackenzie does indeed allow of such an exception, for the "father of British ophthalmology," as he has been called, did not belong to his native country only: by the early and numerous translations of his "Practical Treatise on the Diseases of the Eye," he soon became well known to the German, French, and Italian-speaking ophthalmologists of his time. $\mathrm{He}$ thus deserves that his memory be kept in honour on the Continent as well as in Scotland, and I am glad of the present opportunity to bring a modest contribution from abroad to the homage due to the founder of the Glasgow Eye Infirmary.

There is a second name which ought not to be forgotten to-day, that of the last Donee of the William Mackenzie Medal, Edward Treacher Collins, whose recent death has been a sorrow to all who knew him. I do not intend to repeat what has been already said about his scientific and professional activity; all these particulars have been thoroughly developed in the obituaries written, e.g., hy Leslie Paton for the Brit. Jl. of Ophthal., and Van der Hoeve for the Klin. Monatsbl.f. Augenheilk. I simply wish to add my own testimony to theirs, remembering the skill, kindness and dignity he showed as President of the meeting held at Scheveningen in order to prepare the Congress of Amsterdam. If this first international conference after the war passed off quite smoothly, it was surely due to the calm and friendly manner in which Treacher Collins led the discussions. I am proud to have been appointed as his successor to. the honours of the William Mackenzie Memorial, and I deeply regret that, owing to the circumstances which hindered my accepting the Medal last year, I could not have the privilege of meeting him on that occasion.

Gentlemen, I have been informed, it is usual that the recipient of the William Mackenzie Medal should deliver an address "on some subject connected with ophthalmology," and the members of

* The Willaam Mackenzie Memorial Lecture, 1933 
the Committee suggested that they would like to have a lecture concerning detachment of the retina. As I have already written a number of papers on the subject, it will not be as original and new as Treacher Collins' address on "The Physiology of Weeping," although a little similar to it in one respect, for, with a single change in the pronunciation, instead of formation of tears in the eye, I am going to deal with formation of tears in the retina.

I had to speak three years ago, according to the wish of the Oxford Ophthalmological Congress, on detachment of the retina with special reference to my own method of treatment, giving a short historical account of my studies and first achievements in the matter. I think therefore I should principally devote the present address to what other ophthalmologists have done or brought forward in the meantime. In doing so, I of course do not intend to give a full statement of all the papers which have been issued on retinal detachment for about five years; this single task would be beyond both my power, and your own patience, for, according to the witty remark of an American colleague, ${ }^{1}$ the flow of literature on detachment of the retina was a few years ago a mere trickle, but since then it has become a veritable flood, so that, sending me a reprint from the year 1915, he dated it "anno VIII B.T.D." meaning "before the deluge." Moreover, some of the papers among the actual flood would deserve to be summarized in the drastic manner which the late Professor Michel of Würtsburg and Berlin was cruel enough to use sometimes in his yearly account of the ophthalmological literature: "Das Wesentliche im Titel," which means, "The title contains all that is essential."

In order to get a general view of the evolution of ideas concerning retinal detachment within the last five years, we have to consider separately five points :

1. First, the frequency of holes or tears detected in the detached retina (speaking only of so-called idiopathic or spontaneous detachment).

2. The importance of holes or tears in the beginning, and extension of the detachment.

3. The cause and mechanism of the formation of holes.

4. The conditions of successful treatment.

5. The best way to fulfil those conditions.

1. The first step, as I am pleased to acknowledge, had already been made on British soil: Sir William Lister, for instance, was well aware that holes in the retina "are often seen and can be found more frequently than those may believe who are not in the habit of

\footnotetext{
${ }^{1}$ E. L. Jones, Reprint from the Annals of Ophthalmology, July, 1915.
} 
searching for them"; he added that "they probably occur a good deal more often than they are found by those who do look for them." In his handbook, Swanzy also wrote that in many cases a rent in the detached retina will be discovered. This opinion was nevertheless far from being generally accepted, in spite of having been formerly uttered by de Wecker, Leber and Nordenson; most practitioners and treatise writers used to regard the holes in detached retina as exceptional or did not mention them at all. I could quote several well-known ophthalmologists and even University lecturers who, in all their practice, had never seen or recognized a retinal tear, and one of them told me quite frankly that he and his colleagues believed I was suftering from a kind of monomania for holes, as I again and again spoke of their constancy in detachment. Happily, just before I could be sent to a special home for incurable monomaniacs, evidence was given by an increasing number of trustworthy ophthalmologists, who thought it was perhaps better to look for the holes than to deny their presence without taking the trouble of searching for them.

Thus Weill was able in 1929 to find a tear in 10 cases of 11 , Jeandelize and Baudot (1930) claimed 12 tears in 14 cases, Clausen 11 in 12, Vogt 23 in 25, Veil and Dolfus 42 in 54, Sabbadini 59 in 72 , and Weve 29 in 32 cases, which makes an average of 86 per cent. positive results. Shapland's report from Moorfields Hospital states that more than 100 cases out of 134 showed a hole or tear, the "disinsertions" or anterior dialyses being particularly frequent as in Weve's statistics (which might depend on the cases of injuries being not counted apart from the spontaneous ones). Lindner remarks that the relative frequency of the tears increases regularly with the experience of the searcher, and Arruga gives the figure of 90 per cent. in recent cases, after he had found holes in 30 per cent. only when his attention was first drawn to that point by his stay at Lausanne.

This unexpectedly high proportion of positive cases is the more remarkable in that we know how many causes might make a tear escape notice. Some rents are so large that they are misleading, the part of the choroid deprived of retina being taken for healthy, on account of its seemingly normal red appearance, for instance in cases of total reflection of the upper half of the retina upon the lower half, as in the case described by Ballantyne; I know several instances of such an illusion. More often a hole will escape notice because it is too peripheral or too small, or concealed behind lens or vitreous opacities, so that it requires a great deal of time and patience to discover it. Such a search is nearly impossible if one is in a hurry or if disturbed by noise or talking in the neighbourhood. In a rather humorous article in the Brit. Jl. of Ophthal., Bruce Hamilton states the following aphorism of a colleague of his, 
who had been witnessing his search: "There is only one thing more tedious than looking for a hole oneself, and that is watching someone else looking for it." I know myself something still more tedious: "Looking for a hole whilst someone else is watching you!" Taking all these difficulties into consideration, we may conclude from actual experience that there is no loose detachment of retina without any hole or tear.

(Here a demonstration was made of misleading ophthalmoscopic appearances or hardly noticeable retinal tears.)

2. Many ophthalmologists, although not denying that rents in detached retinae are frequent, clung to the old idea that they were secondary to detachment, being due either to a kind of maceration of the tissue, or to its bursting under the pressure of a choroidal exudate. The first hypothesis fell down before the fact that rents are more frequently found in fresh cases of detachment than in older ones; the second does not agree any better with many clinical and anatomical findings; for instance: (a) Holes may sometimes be seen before the detachment has formed, or before it has shown any tendency to spread into the other parts of the fundus. (b) In balloon-shaped upper detachments, large rents are often seen on the most prominent part of the balloon, the formation of which ought to have been hindered by the rent allowing the liquid to pass through. If several holes exist in the balloon, which is not infrequent, their formation from behind is still more improbable, because, as Sir William Lister was right in setting forth, only a single hole could be produced, for "directly a breach takes place, the pressure on the two sides of the retina would be equalized."* (c) If examined in a fresh detachment, the retroretinal fluid proves to be much poorer in albuminous substances than any choroidal exudate or transudate, its chemical constitution being very similar to that of the vitreous humour; Arruga's contribution at the recent Congress in Madrid was quite explicit on this point. (d) That even a strong sub-retinal pressure does not easily cause the retina to burst, is shown by the detachments in pregnancy or by those accompanying a tumour, where neither tear nor hole forms in spite of an extremely tense ballooning of the retina.

(Demonstration of a large rent that preceded for many weeks the spreading out of a detachment, of prominent balloons with big rents, and of others without rents in cases of tumours or of Coats' disease.)

These facts and many others of daily observation should have been sufficient to prove that the holes or tears are not, as a rule, a consequence of detachment, but that on the contrary they allow the detachment to form and to spread; nevertheless the old ideas coild not be overcome until the demonstration was made that searing up

\footnotetext{
* Transactions of an International Congress at Washington, 1922.
} 
the edges of the tear by the cautery, and stopping in this way any passage of liquid through the hole, was followed by complete and permanent reposition of the detached retina, unless a new hole should have formed in another place. This evidence was so striking that it at once thoroughly convinced such operators as Vogt, Arruga, Lindner, Loewenstein, Bruckner and later many others, who soon referred to their own successes, not to speak of the numerous oculists who could testify to their great astonishment, that a patient whom they had dismissed two or three weeks before with a detachment they believed to be hopeless, had returned with a perfect state of re-application after a single thermopuncture. I could make an interesting library of the letters I have received on that subject. Some colleagues acknowledged that, but for the "wafer" marking the site of the cauterization, they have found no trace any more of the detachment, and could have doubted whether the operated eye had really been affected. A patient wrote from Tallin (Latvia), that his oculist asked him what he had done with his eve, saying: "You have exchanged it for another!" Vogt concludes from his own experience that calling in question the causal importance of retinal holes for detachment would simply be "denying the evidence." The few who still express some reserve, like Wessely, upon the demonstrative value of closing up a hole, ought to recollect that this proof on the therapeutic ground, was to us a supplementary proof, a so-called supererogatory one, our conviction being previously fully based on many anatomical and clinical reasons.

3. Concerning the formation of the tears, it is well known that Leber and Nordenson explained it by the retracted vitreous dragging on the anterior surface of the retinal tissue, but that later on Leber himself modified his first opinion by incriminating new formed preretinal membranes for the folding and tearing of the retina. On the other hand, Hanssen showed that more or less large holes in the peripheral retina may result from a chronic atrophic process in high myopia. That such atrophic holes might directly provoke a detachment is doubtful : in fact in none of the eyes examined by Hanssen was the retina detached. Moreover we know how often a wound of the retina (for instance a cut made in order to extract a foreign body from the interior of the eye) may heal without being followed by detachment. If the vitreous body is normal, we must admit that the hyaloid membrane (be it a true membrane or only a thickening of the outer layers of the vitreous gel, it does not matter) acts like a cork in front of the opening of the retina. Even the gyral movements of the vitreous are likely to have no effect on the retina as long as its membrana limitans is intact. If however the vitreous body is itself detached and a certain amount of fluid has collected between its mass and the retina, this fluid can make its way through the hole and produce the detachment. 
The action of the vitreous is much more evident in all cases of crescentic, arrow-headed or horse-shoe-shaped rents, especially when the retinal flap is projecting into the vitreous space, or has been totally torn away and is to be seen floating in front of the hole. We again meet here with Sir William Lister, who also expressed the opinion (Washington, 1922) that posthaemorrhagic vitreous tags, if attached "at one end to the retina and at the other to a contracting vitreous, would be sufficient to cause a rent." Vogt, who at first gave the main importance to atrophic holes, later fully recognized the dragging force of the degenerated vitreous and Lindner emphasized it still more clearly. Nevertheless the importance of the pathological changes in the vitreous has not yet found full recognition. They are indeed not easy to observe with the ophthalmoscope and still less on microscopic slides. The vitreous mass being normally free from cellular elements, its changes of volume and density hardly modify its transparency and remain imperfectly revealed by histological staining. A good example of this cause of error is given by Arruga, who, in his sincere and conscientious report for the International Congress in Madrid, reproduced among others some slides out of my own collection; in his coinment upon one of these slides from a case of rather old detachment with extreme shrivelling and thickening of the vitreous mass, Arruga states that the latter shows no alteration worth mentioning, especially no infiltration or organization of any kind.* If he had seen the macroscopic specimen of the same case, he would have concluded quite the opposite. I must emphasize here, as I have already done on several occasions, that macroscopic study of the vitreous body is far more instructive and demonstrative than the microscopic one.

(Demonstration with epidiascope and stereoscope of anatomical specimens and photographs illustrating the mechanism of retinal detachment and tears due to adhesions with the retracting vitreous mass.)

Summarizing the pathology of retinal detachment as confirmed by the many observations made during the past few years, we may say that the presence of a hole or of several holes is a necessary condition of any loose detachment, but that it is not the only one : previous or subsequent alterations of the vitreous body allow these holes to become the starting point of a progressive detachment.

What about the second theory of Leber regarding new formed membranes as the cause both of tears and retinal folds? His error was the same as the above mentioned, giving a too exclusive importance to microscopic slides. If on one hand the usual histological stains are not sufficient to reveal many particulars of the vitreous body, they exaggerate on the other hand the relative importance of the cellular strands or trails which are often to be

\footnotetext{
* Etiologia y Patogenia del desprendimiento de la retina, p. 67.
} 
found on the inner surface of the retina, especially in late stages of detachment. It seems impossible to understand how these membranous formations could provoke the atrophic holes, or the arrow-headed and horse-shoe-shaped rents with their flaps projecting into the vitreous, or totally torn away from the tear. As far as I know, Leber's last ideas have not been supported by any other ophthalmologist, and it has been generally admitted that the "præretinitis" he described, was only secondary to detachment. The spreading of the new-formed membranes on the inner layers of the retina should rather reinforce them, and might even possibly contribute in some cases to the spontaneous sealing up of a tear. On the other hand, by bridging the folds of the retina, the membranes can "ankylose" them and make them definitive.

The truth is that cellular formations developing to some extent previous to the detachment are frequently seen with the ophthalmoscope in the vicinity of tears or without any apparent connection with them, being also present in cases of non-detached retina, or in the second eye of a patient affected with detachment. They are mostly concomitant with, or indicative of, a similar penetration of epithelial cells from the ciliary circle into the vitreous body, as shown by the slit-lamp or with the microscope; but, as Samuels rightly remarks, ${ }^{*}$ with the latter instrument, the homogeneous fibres or lamellae to which they may be clinging are not visible, because they take no stain.

In conclusion, the great progress which has been made for several years in searching for retinal holes must be completed by more attention being given to the changes in the vitreous. This question is not only of theoretical interest; we shall see that it has a practical importance with respect to treatment.

(Showing pictures of preretinal formations and the typical forms of the rents due to traction inward by the vitreous tags or adhesions).

4. The conditions of successful treatment.--There is no need to insist upon the uncertainty which prevailed up to a few years ago about the object to be aimed at in treating a retinal detachment. What was most important? Giving exit to the subretinal fluid?About forty different methods were known for that purpose-Creating adhesions between detached retina and choroid? No less than eighty techniques had been tried and praised one after the other, being often combined with those of the former group, and nearly every one had been able to register some successes, at least in the same proportion as in the cases left without any treatment. What always remained unknown was the reason why in one case there had been a happy result and in another case a complete failure.

Our present knowledge about the significance of holes in the

\footnotetext{
* Oxford Ophthalmological Congress, 1930.
} 
detached retina can as well explain the former rare successes as the much more usual failures. A single puncture giving exit to the subretinal fluid might have brought back the flap of a rent into its right place; thus, if rest of the eyeball were strictly observed, a momentary or even permanent closing up of the hole could result. I know such examples of several weeks' duration: once 48 hours lying on the side corresponding to the rent was sufficient to bring about the complete reposition of a detachment that had lasted for several months; after four weeks, probably under the influence of a strong movement of the eye, the operculum of the tear became removed, being visible with the ophthalmoscope in the vicinity of the hole, and the detachment reappeared in a few days.

With the numberless methods that had been used to make adhesions between the retina and choroid, the operators were sometimes lucky enough to seal unconsciously the edges of the retinal holes, and thus a full recovery was secured. It is more and more evident that we have here the explanation of the cures claimed by the practitioners who, like Sourdille of Nantes, still consider there is no need to pay attention to the retinal holes or tears.

There is no doubt that the great improvement, we notice for a few years in most statistics concerning the treatment of detached retina, is due to the fact that this treatment is more methodically done. An ever increasing number of operators have recognized the importance of sealing up the holes or at least of blocking up any passage of liquid through them into the subretinal space. We have here the main step made in the evolution of ideas within the last few years. If we remember that, till a short time ago, very distinguished practitioners were expressing the opinion that any active treatment " was to be refrained from," or should be made only " to mark time so that our patients might have the satisfaction of feeling that something was being tried," we may feel happy to see how the former scepticism has turned into more hope and confidence, as is clearly shown by recent papers. For instance, Bartels writes : "The question now is not any more whether one must operate on a detached retina, but how best we are going to do the operation," and Engelking: "Not operating must now be regarded as a professional fault."

Such a change of mind among ophthalmologists had been forseen indeed by Vogt when, relating in $1930^{*}$ the results of his thermopunctures, he wrote: "A time will come when such cures will be considered as quite a natural thing, but at present they appear to us and to our patients like a kind of wonder, in the possibility of which a short time ago nobody would have believed."

The anatomical effect to be aimed at has been sometimes discussed in a somewhat Byzantine way: should we speak of sealing

*Klin. Monatsbl. f. Augenherlk., Vol. LXXXIV, p. 320. 
the hole itself or of sticking its edges to the choroid ? The debaters on this matter were not aware of the author's first papers: he never stated or thought that closure of the hole was to be secured by causing union of the margins (cf. Larsson, p. 3), unless doing so were possible by direct reposition of the flap; from the beginning he made no essential difference between the various ways employed to block up the passage of liquid through the retina. The first two drawings he published show the searing scar on the edge of the tears (Soc. fr. d'Ophtal., 1925) and speaking of his method before the German Congress of Heidelberg in 1925, he explained that the retinal tear was to be incorporated "directly or indirectly" into the cicatrising process. On other occasions he emphasized the necessity for proceeding according to the particularities of each case, and he pointed out, for instance, that against a large "disinsertion" the only plan was to make a kind of barrier in front of it, i.e., a line of adhesions, in order to stop the progress of the detachment towards the central region of the eye (thus two Viennese operators could have spared themselves the trouble of arguing for the priority of "demarcating" the diseased part of the retina).

Of course, if a hole was small, or a tear narrow, the most favourable manner of blocking it was to include the edges in the same scar, and under such circumstances the cautery, if used for the operation, had to strike as exactly as possible the centre of the retinal opening. This "optimum" is to be aimed at, but does not always belong to the realm of possibility.

There is another point where the scope of operative treatment seems not to have been thoroughly understood. The permanent blocking up of the retinal hole by adhesions to the choroid must include a sufficient resistance to the dragging force of the vitreous body. The actual tendency is to forget or neglect this second indication. That is the reason why I insisted at some length on the rôle of the vitreous tags in the formation of retinal tears. The same considerations are going to lead us in studying our last point, which concerns the best means of securing a complete and permanent blocking up of the tears.

5. A cauterization made with the Paquelin cautery through the sclera on the site of the tear was the first means I used for the purpose of creating between the retina and choroid an adhesion sufficient to check the traction of the vitreous and to block up the passage of fluid into the subretinal space. It had the astonishing result that not only this passage and any further progress of the detachment were stopped, but that also the fluid already collected under the retina had disappeared and the detachment showed a complete reposition. This same result was obtained even in cases 
where a detachment, having already changed its initial position, was occupying the lower half of the eye, whilst the operation had been made, on account of a superior rent, in a region apparently reapplied, with a rather scanty escape of liquid from the eye. It would seem therefore that the cautery had not sealed up at once the scleral and choroidal wound, but that the adhesions had formed gradually, allowing the subretinal liquid to pass through during the first hours; this trickling may be favoured by the position of the head of the patient, leaning backward if the tear be in the upper part of the eye, and keeping his head higher on pillows in the case of an inferior rent.

The scars left by the Paquelin cautery, if looked at five or six days later, are in most cases plainly limited, similar to an avascular optic disc, with a pigmented edge, sometimes surrounded by a greyish somewhat prominent ring, which I consider to be coagulated mass; this coagulum which disappears little by little from the second to the third week. The searing scars from the galvanocautery are mostly more irregular and smaller, necessitating generally a greater number of thermopunctures if the rent is large. The average of Paquelin punctures in my own statistics were three for two rents to be blocked up, whilst the statistics of Vogt, who from the beginning used the galvanocautery, gave three operations for one rent; but I must remark that he succeeded in closing up with one single galvanopuncture a very large rent. I should have expected to find at least three punctures necessary. Knapp, of Basle, found the comparison of these two instruments to be in favour of the Paquelin; Di Marzio and Sabbadini, after using the one a galvano, and the other a Paquelin, did not notice any difference in their results, while Mayou wrote me lately that the Paquelin was now abandoned in Great Britain on account of the danger of haemorrhages. This divergence of opinion must depend upon differences in the technique or in the heating power of instruments. According to my own experience a blunt galvanocautery has no advantage over the Paquelin; it loses its heat more easily and its action is more slow, so that it must be left a longer time in the wound (Lindner kept it up to 20 seconds in the eyeball!), which might be the cause of the secondary shrivelling of the retina that made Lindner give up the cautery methods. In fact I met with a similar complication myself in the only case where I imitated Lindner's long cauterization. The sharp pointed galvanocautery, that Vogt actually uses, has not the same inconvenience and will easily allow two or three punctures to be made at the same sitting, whilst two are as a rule the maximum possible with the Paquelin. In this matter it is better that each operator should proceed with the instrument that has given him the best results.

The cautery method was first abandoned at Vienna under the 
charge of producing secondary tears in the vicinity of the scar. This reproach was widely spread by non-medical papers in a way that does not agree with Swiss (and I guess no better with British) rules of medical ethics, so that we could not discuss it until Lindner himself brought up his own views on the matter in a medical journal.*

The complaint of the cautery producing secondary tears by a necrosis of the retinal tissue on the edges on the scars is not in conformity with the experience of most operators, in spite of having been repeated in many papers. My feeling and that of my former assistant, Miss N. Bercioux, who witnessed Lindner's operations, is that the so-called secondary tears were mostly the remainders of a not completely sealed up rent; if not so, they must have resulted from some error of technique, probably from too long cauterizing. The inconvenience and dangers of thermopuncture have been openly acknowledged by me in my different papers. (1). Risk of abundant haemorrhage into the vitreous, either at the moment of the operation or some days later. (2). Difficulty or even impossibility of making more than one or two punctures at the same sitting, which necessitates a second or a third operation in cases of a very large rent or of uncertain location of the hole. In that respect the chemical cauterization of the choroid with potash through trephined holes in the sclera could afford some advantages, but it was a very long, tedious and delicate performance, and its results have been sometimes very unfavourable: e.g., diplopia caused by too wide adhesions between conjunctiva and muscles of the eyeball, dystrophy of the cornea, etc.., so that many operators' and Lindner himself have given it up.

Within the last three years, a quite different manner of blocking up retinal tears has been made known by Weve, Larsson, Safar and Meller, Genet and others, availing themselves of the coagulating power of the high frequency current, either through the unperforated sclera by means of a ball-shaped electrode, or by means of needle electrodes which are made to penetrate into the scleral tissue till reaching the choroid and the retina. This method seems to offer the same advantages as the chemical cauterizations: less danger of haemorrhage, possibilities of numerous adhesions made in one sitting and smaller damage to the retina. Its technique and effects have been already exposed to English readers by Larsson, King and Shapland, but it is as yet too early to give a definite judgment upon them. Whilst many years elapsed before any attempt was made to follow by thermopuncture the example of the initiator, the confidence had grown so much greater about the possibility and usefulness of blocking up the retinal holes, that both the chemical

*Arch.f. Ophthal., Vol. CXXVII, p. 177, 1931. 
method and that of electro-coagulation met at once with many imitators, so that we heard about cures and of statistics before the technique was fully elaborated.

My opinion is that we must not reach conclusions too hastily, a few weeks or months after the first experiments. Above all we must refrain from generalizing, for it is likely that each of the proposed techniques has its own advantages and indications, but also its contra-indications, which ought to be fully made clear. We are threatened to be flooded, not only by the papers, but even by the different methods or submethods of operation, and it begins to be difficult to make order in that flood. Like the above-mentioned American colleague, we must save what is worth saving among our experiences from the B.T.D. time, i.e., from "before this new deluge."

First we may distinguish those operative techniques the purpose of which is to act deeply, that is, to produce adhesions common to the sclera, choroid, retina and vitreous humour, if the latter has formed and kept noxious tags to the retina. To this group belong the thermopunctures with Paquelin or galvanocautery and the technique of Weve with needles, as described in his monograph.

A second group includes the methods aiming at a rather extended surface or line of adhesions, the action of which must remain limited to a reactive process in the choroid, so that the outer layers only of the retina may be implicated in the adhesive scar. The endeavour not to damage the inner layers of the retina and particularly not the vitreous mass seems hereby justified in as much as one deals with merely atrophic holes or with other tears that might be supposed to be free from any traction exerted by the vitreous mass or strands. Lindner, Weve and Safar acknowledge frankly that their techniques on the surface are not practicable in cases where the retina is not in contact or nearly so with the choroid. My experience quite agrees with this: in all cases where the flap rises slightly above the level of the rent, it cannot be employed as a useful material for closing up the hole, and one has to resort to the indirect way of circling the hole or excluding it by a wall of adhesions in a large sector of the retina. Further observations will show whether these superficial but multiple adhesions are safe enough, or if relapses won't be more frequent than after cautery puncture. Against a rough adversary, we want rough weapons, and the rather heroic means of plunging the white heated Paquelin a few millimetres into the vitreous is probably to be resorted to, if the badly retracting vitreous makes necessary an heroic struggle to save the eye. I, myself, as well as Vogt, had thus some successes which I think never could have been attained with the more complicated and more vitreous-saving methods. The discrimination of such cases depends greatly on the state of the vitreous and the kind 
of its alterations. That shows the importance of not neglecting this study besides the looking for and locating of the tears.

Judging from experience up to date I would think that if some cases prove to be specially fit either for thermopuncture or for electro-coagulation, others should be submitted to a combination of both methods. In the presence of a large rent in a rather dubious retina, I first used the surface diathermy, then punctured the middle of the rent with the cautery; for smaller rents with a loose flap, I tried a single thermopuncture, and if the scar proved to be not quite sufficient, I completed it in a second sitting with some endothermic needle punctures on the site of the remaining part of the tear.

The main danger of the recent methods is that some operators believe they may refrain from looking carefully for the tears and locating them exactly. I am already aware of several failures due to that wrong idea; it only postpones the main difficulty until the moment of the operation. Lindner himself, as well as Weve and Safar, do not dispense with localisation. Making a barrier in front of the sector of the retina where a tear is only supposed to be, is a last shift for the cases with no other possibility, and will often not prevent a relapse.

Moreover, the difficulty of accurate localising has been much exaggerated, not to speak of the many ingenious instruments that have been proposed (the description of which would be much too long to be given here). The author's mere subjective method (as described in English by Frank Juler and J. B. Lawford in the Brit. Jl. of Ophthal., 1930, and by Anderson in his monograph) has proved to be as a rule sufficiently exact, not only to himself, but also to many others like Vogt, Arruga, Elschnig and Stein, Cavara and Bencini, Di Marzio and Sabbadini, Veil and Dolfus, Goerlitz, etc., as well as to the members of the Surgical Staff of Moorfields Hospital, who put it into practice. Of course errors remain possible on account of the variations of form and refraction from eye to eye, and if the author is asked by a patient whether he is sure to reach by his first attempt the very site of the tear which is to be aimed at, he will answer that the best shot cannot promise before shooting to reach the bull's eye, and that his own grandgrand-father William Tell himself, the Swiss Wallace, an homonym and contemporary of the Scottish hero, was not quite certain he would strike with his first arrow the apple on his son's head, so that he kept a second arrow in his belt. This topical argument easily convinces the patient and he accepts the eventuality of a second operation, the more that, if the first searing scar is not sufficient, the improvement is generally so marked that it gives igreat encouragement.

In this matter, indeed, as in other ones, the evolution of ideas 
means always increasing exigencies. The first instances of cured detachments that I published, in some of which two or three cauterizations were necessary, with one to three months treatment, seemed to be a great step forward compared with the older methods; but if Stephenson's railway was a great improvement in comparison with the coaches of Dickens' time, railways are now despised by motor cars, and the latter by aeroplanes. One claims now to get rid of a detachment in one single sitting ; let us wait to see if safety will go together with rapidity.

I don't wish to be misunderstood. If I warn against too great a haste in judging, it does not mean any prejudice against new methods of treatment. I never pretended that the first means I resorted to in order to block up retinal tears was the only or the best one. In the short address I gave at Oxford in 1930, at a time when no other technique but the cautery puncture was known, I clearly expressed my opinion that the operation could be made in quite a different manner from mine, and that the "why" was much more important than the "how." Already in 1921* I suggested that good results might be hoped for from chemical cauterizations on the choroid through trephine holes in the sclera, which is just the way Guist and Lindner have been practising, about 10 years later, with potash. I shall greet with pleasure and look forward to any improvement that may be made in order to increase the cases where detachment can be cured, and I hope that Weve's prevision of future successes in 85 per cent. of the cases with the help of electrocoagulation will prove not to be too optimistic, the last improvements in his technique, I just could see at Utrecht, allowing even a greater confidence in fresh cases.

The author is grateful to all fellow-ophthalmologists, who endeavour to develop the means of closing up the retinal tears he first put into practice; the only thing he requires is that his conviction be discussed with serious arguments and precise observation and not by mere suppositions or by negation only. "Errare humanum, perseverare diabolicum." There is no dishonour in changing his mind if new circumstances happen to justify doing it. Surely the esteem Sir William Lister enjoys among British ophthalmologists has been increased by the open manner in which he declared before the Ophthalmological Society that he had been mistaken about the significance or hopelessness of the retinal holes. ${ }^{1}$ Vogt was right to say in Madrid that those who, judging without proving, cling to their theoretical opinion, do not deserve to be taken in earnest, for, according to the present lecturer's remark in Oxford, truth is not a matter of personal preference, but must be accepted as it is. The truth is that holes or tears are a condition of any loose detachment

*Ann. d'Ocul., Vol. CLVIII, p. 193. 
and that in inost cases previous changes in the vitreous take part in their formation. Instead of yielding to the evidence, some objectors have forced their imagination, if we may quote the words of Arruga (p. 131), and "herewith they only complicated the question."2

A few of the objectors have opposed their experiments on rabbits which did not agree with our findings in human eyes. I do not think this kind of comparison is conclusive. Others came on the field with arguments still less decisive, for instance our most obstinate adversary, Dr. Sourdille, of Nantes. In a striking contrast to a British ophthalmic reporter, ${ }^{3}$ who mentioned that "good news had come from Switzerland," Sourdille began a Philippic against our views, by pointing out that they were those of a "foreign school," which "in papers of every language and before learned societies of numerous countries" was proclaiming a rapid and infallible method for the cure of detachment ${ }^{4}$. . . Confiteor! The principal culprit confesses that he went twice to Heidelberg and spoke there in German; later he accepted an invitation to go to Oxford and to deliver an address in English. To-day he has come to Glasgow and regrets his inability to speak in Scotch like a Fair maid of Perth ... If he had to apologize for coming, he would simply tell Sourdille like the Apostle to the Hebrews: ". . . the good news has been first spoken to you (and in your own language); but seeing ye put it from you . . . lo, we turned to the Gentiles."

Gentlemen, "Gentile" (in French "gentil ") means also "noble" or "kind": gentilhomme=gentleman. Visiting to-day my gentle colleagues of Scotland, I feel deeply touched by their kindness. After I had been hindered by sad circumstances from accepting last year the "Mackenzie Memorial Medal" and had suggested that it should be given to another, you kept to your purpose of bestowing it on me and you postponed. by one full year the present ceremony. For this kind attention I am specially grateful to you.

\section{REPERENCES}

1. Trans. of the Ophthal. Soc., Vol. LI, p. 160.

2. Etiologia e patologenia del desprendimiento de la retina. Madrid, 1933.

3. Frank Juler.-Brit. Jl. of Ophthal., 1930.

4. Bull. de la Soc. Ophtal. de Paris, p. 684, 1929. 